\title{
Moderate Hypoxia Down-Regulates Interleukin-6 Secretion and TLR4 Expression in Human Sw.71 Placental Cells
}

\author{
Koumei Shirasuna ${ }^{a}$ Narumi Shimamura ${ }^{a} K_{\text {Kotomi Seno }}{ }^{a}$ Ayaka Ohtsu $^{a}$ \\ Shogo Shiratsuki ${ }^{a}$ Akihide Ohkuchi ${ }^{b}$ Hirotada Suzuki ${ }^{b}$ Shigeki Matsubara ${ }^{b}$ \\ Shiho Nagayama ${ }^{b}$ Hisataka Iwata ${ }^{a}$ Takehito Kuwayama $^{a}$ \\ a Laboratory of Animal Reproduction, Department of Agriculture, Tokyo University of Agriculture, \\ Atsugi, Kanagawa, ${ }^{b}$ Department of Obstetrics and Gynecology, Jichi Medical University, Shimotsuke, \\ Tochigi, Japan
}

\section{Key Words}

Hypoxia $\cdot$ Placenta $\cdot$ Interleukin- $6 \cdot$ Inflammation

\begin{abstract}
Background/Aims: The placenta is a vital organ for pregnancy. Many in vitro placental experiments are conducted under $21 \% \mathrm{O}_{2}$; however, $\mathrm{O}_{2}$ tension could influence cellular functions, including cytokine secretion. We investigated the effects of oxygen tension between moderate hypoxia $\left(5 \% \mathrm{O}_{2}\right)$ and normoxia $\left(21 \% \mathrm{O}_{2}\right)$ by testing the hypothesis that moderate hypoxia regulates cellular phenotypes differently from normoxia in human trophoblast cells. Methods and Results: Sw.71 trophoblast cells were incubated under normoxic or moderately hypoxic conditions. Cells were also treated with lipopolysaccharide (LPS) as a Toll-like receptor 4 (TLR4) ligand inducing inflammation. Interleukin-6 (IL-6) as an inflammatory cytokine was determined, and TLR4, hypoxia-induced factor- $1 \alpha$ (HIF1 $\alpha$ ), and reactive oxygen species (ROS) production were detected. Moderate hypoxia increased HIF1 $\alpha$ expression and cell proliferation and acted by two different mechanisms to decrease IL- 6 secretion compared with normoxia: it limits the TLR4 expression and ROS production. Treatment with cobalt chloride as an HIF1 activator inhibited IL- 6 secretion and TLR4 expression; this effect was reversed on treatment with PX-12 as an HIF1 suppressor. Conclusion: IL-6 secretion, TLR4 expression, and ROS production, classical markers of inflammation, are down-regulated by moderate hypoxia, and HIF1 $\alpha$ and ROS have a potential to regulate these responses in human trophoblast cells.
\end{abstract}

Copyright (c) 2015 S. Karger AG, Basel

\section{Introduction}

The placenta is a vital organ for establishing and maintaining pregnancy. During early pregnancy in humans, the placental tissue has a significantly moderate and lower oxygen

Koumei Shirasuna, PhD

KARGER 125
Laboratory of Animal Reproduction, Department of Agriculture,

Tokyo University of Agriculture, 1737 Funako, Atsugi, Kanagawa, 234-0034 (Japan)

Tel. +81-46-270-6588, Fax+81-46-247-4338, E-Mail ks205312@nodai.ac.jp 
concentration because the extravillous trophoblasts invade the spiral arteries and prevent the flow of maternal blood, resulting in a physiologically hypoxic environment $[1,2]$. However, the excessive hypoxia associates with cellular and tissue dysfunction. Preeclampsia, a pregnancyspecific hypertensive syndrome, complicates $5 \%$ of all pregnancies worldwide. Recently, it is reported the placentas of women with preeclampsia and fetal growth restriction display significant genome and proteome differences compared with normal pregnancy $[3,4]$. It is strongly recognized that severe hypoxia within the placenta is one of key pathogenesis of preeclampsia [5, 6]. High levels of circulating soluble Endoglin (sEng, a cell-surface coreceptor for transforming growth factor- $\beta$ ) and soluble fms-like tyrosine kinase (sFlt-1, a receptor for VEGF) of placental origin may contribute to the pathogenesis of preeclampsia [7, 8]. Actually, the release of sFlt- 1 and sEng under severe $\mathrm{O}_{2}$ tension (1\%-2\%) was stimulated in human placental cells obtained from the placentas of preeclampsia patients $[9,10]$. In addition, pathophysiological changes of preeclampsia include inflammation and immune cell activation. Indeed, a generalized inflammatory response by cytokines, such as interleukin (IL)-6, IL-1 $\beta$, and tumor necrosis factor- $\alpha(\mathrm{TNF} \alpha)$, have been considered to be the main pathological features of preeclampsia [11-13]. Therefore, the investigation of $\mathrm{O}_{2}$ tension is crucial to understand physiological and pathophysiological mechanism of placenta.

Oxygen supply is crucial for most tissues and cells in maintaining physiological functions. Although many tissue culture experiments are conducted under normal $\mathrm{O}_{2}$ condition $\left(21 \% \mathrm{O}_{2}\right), \mathrm{O}_{2}$ tension in tissues and organs is generally much lower than that found in the atmosphere $[14,15]$. It is reported that the partial pressure of oxygen in the placenta is $5-6 \% \mathrm{O}_{2}$ on 12 to 13 weeks gestation [16]. On the other hand, in severe hypoxia conditions, cells shift their metabolism from mitochondrial respiration to anaerobic glycolysis, resulting in the production of reactive oxygen species (ROS) and a decrease in ATP availability [17]. These findings suggest that $\mathrm{O}_{2}$ tension could exert an influence on organ and cellular function.

Inflammation plays a pivotal role in the regulation of physiological and pathophysiological responses. Pro-inflammatory cytokines secreted from many types of cells, such as immune cells, endothelial cells, and placental cells, critically mediate the inflammatory response. Indeed, numerous immune and inflammatory cells reside in the placenta and play a crucial role in the inflammatory responses via cytokine secretion, which may affect placental development and function [18]. However, excessive inflammatory responses in the placenta can result in preeclampsia [19]. Although severe hypoxic stress (1-2\%) in macrophages upregulates inflammatory responses, such as the increase of IL- 6 and IL-1 $\beta$ [20], moderate hypoxia (5\%) in alveolar macrophages led to an attenuated secretion of monocyte chemoattractant protein-1 [21], suggesting that $\mathrm{O}_{2}$ tension associates with the degree of inflammatory response. However, the effect of moderate hypoxic condition for inflammatory response in the placental cells is not clear.

James et al. [2] suggested that as a control, an appropriate oxygen concentration of more or less moderate hypoxia $\left(5 \% \mathrm{O}_{2}\right)$ may more accurately represent the physiological conditions in vivo. In the present study, we investigated the effects of oxygen tension under moderate hypoxic $\left(5 \% \mathrm{O}_{2}\right)$ and normoxic $\left(21 \% \mathrm{O}_{2}\right)$ conditions on inflammatory response by testing the hypothesis that moderate hypoxia regulates inflammatory cytokine secretion differently than normoxic conditions do in the human trophoblast cell line.

\section{Materials and Methods}

\section{Cell culture}

Human first trimester trophoblast cells (Sw.71, trophoblast cell line) were provided by Prof. Mor G [22] and cultured in Dulbecco's modified Eagle's medium/F-12 (DMEM/F-12; Life Technologies Corporation, Carlsbad, CA) supplemented with antibiotics, sodium pyruvate (Wako Pure Chemical Industries, Ltd. Osaka, Japan), non-essential amino acids (Wako Pure Chemical Industries), and 5\% fetal calf serum (FCS; ICN, Costa Mesa, CA).

The cells were plated at a concentration of $1 \times 10^{5}$ cells/well in a 24-well culture plate (Thermo Fisher Scientifc Inc, Wartham, MA). Sw.71 cells were maintained under standard culture conditions: 5\% 
$\mathrm{CO}_{2}$ and $21 \% \mathrm{O}_{2}$ (as normoxia) or $5 \% \mathrm{O}_{2}$ filled with inert $\mathrm{N}_{2}$ at maximum humidity (as moderate hypoxia). To detect an inflammatory response, the cells were washed twice in phosphate buffered saline (PBS) and treated for $24 \mathrm{~h}$ or $48 \mathrm{~h}$ with or without lipopolysaccharide (LPS, $100 \mathrm{ng} / \mathrm{mL}$, Sigma) as Toll-like receptor 4 (TLR4) ligand containing $0.1 \%$ bovine serum albumin (BSA). To investigate the role of HIF $1 \alpha$, Sw.71 cells were incubated in the presence or absence of cobalt chloride ( $\mathrm{CoCl}_{2}$, Sigma, St. Louis, MO) or Deferoxiamin (Sigma), which are HIF1 activators for $24 \mathrm{~h}$. In addition, to evaluate the effect of down-regulation of HIF1, $\mathrm{CoCl}_{2}$-activated Sw.71 cells were incubated in the presence or absence of PX12 (Sigma), HIF1 inhibitor for $24 \mathrm{~h}$ under normoxia or moderate hypoxia. To investigate the role of ROS, Sw.71 cells were incubated in the presence or absence of Rotenone (Sigma) or, Pyocianin (Wako Pure Chemical Industries) which are ROS stimulators for $24 \mathrm{~h}$ under moderate hypoxia. In addition, to evaluate the effect of ROS elimination, Sw.71 cells were incubated in the presence or absence of N-acetyl-L-cysteine (NAC, Wako Pure Chemical Industries), anti-oxidant for $24 \mathrm{~h}$ under normoxia or moderate hypoxia.

\section{Determination of cytokines}

IL-6, sEng, sFlt-1, IL-1 $\beta$, IL-8 and IL-10 levels were determined using a human enzyme-linked immunosorbent assay (ELISA) kit (R\&D Systems, Minneapolis, MN) according to the manufacturer's instructions.

\section{Determination of hypoxia}

Hypoxic conditions were confirmed using a hypoxyprobe staining kit (Hypoxyprobe Inc, Burlington, MA) according to the manufacturer's instructions. The cells were covered with VECTERSHIELD with 4'6-diamidino-2-phenylindole (DAPI) (Vector Laboratories, Inc. Burlingame, CA). The staining sections were analyzed using a microscope (Leica Microsystems).

\section{Western blot analysis}

Lysates from the cell culture were prepared using RIPA buffer (20 mM Tris, $2.5 \mathrm{mM}$ EDTA, 1\% Triton $\mathrm{X}, 10 \%$ glycerol, $1 \%$ deoxycholic acid, $0.1 \% \mathrm{SDS}, 50 \mathrm{mM} \mathrm{NaF}$, and $10 \mathrm{mM} \mathrm{Na}_{4} \mathrm{P}_{2} \mathrm{O}_{7} 10 \mathrm{H}_{2} \mathrm{O}$ ). The expression of TLR4, HIF $1 \alpha$, and $\beta$-actin were analyzed using SDS-PAGE. After transfer onto poly vinylidene fluoride membranes, non-specific antibody binding was blocked for $1 \mathrm{~h}$ at room temperature using immunoblock (DS Pharma Biomedical Co, Ltd, Osaka, Japan). Then, membranes were then incubated for $24 \mathrm{~h}$ at $4 \mathrm{C}$ with anti-TLR4 antibody (Abcam, Cambride, MA), anti-HIF1 $\alpha$ antibody (Abcam), and anti- $\beta$-actin antibody (Sigma), followed by an incubation for $1 \mathrm{~h}$ with secondary antibody conjugated horseradish peroxidase (HRP; GE Healthcare, UK Ltd, Buckinghamshire, UK). Immunoreactive bands were visualized by Western BLoT Quant HRP Substrate (GE Healthcare) using ImageQuant LAS 4000 (GE Healthcare).

\section{Immunocytochemistry}

The cells were treated in the same manner as that employed for hypoxyprobe staining. After blocking with 5\% BSA in PBS for $1 \mathrm{~h}$, the cells were incubated with the TLR4 antibody for 90 min followed by incubation for $1 \mathrm{~h}$ with secondary antibody Alexa 555 (Cell signaling, Carlsbad, CA). The staining sections were analyzed using a microscope.

\section{Detection of ROS generation}

ROS production was analyzed using CellROX Oxidative Stress Reagents (Life technologies, Tokyo, Japan) according to the manufacturer's instructions. The cells were treated with CellROX reagents for 30 min at a $5 \mu \mathrm{M}$ concentration, washed with PBS three times, fixed with $3.7 \%$ paraformaldehyde for $15 \mathrm{~min}$, and washed in PBS three times. The staining sections were analyzed using a microscope.

\section{Cell proliferation assay}

Cell proliferation was assessed by WST1 assay kit (Roche, Mannheim, Germany) according to the manufacturer's instructions. The assay is based on the enzymatic cleavage of the tetrazolium salt WST1 to formazan by cellular mitochondrial dehydrogenases present in viable cells. Briefly, $1 \times 10^{4}$ cells were incubated in 96-well plates for $24 \mathrm{~h}$, and then cultured under normoxic or moderate hypoxia conditions, followed by a reaction for $3 \mathrm{~h}$ with WST1. The absorbance at $450 \mathrm{~nm}$ was measured using a microplate spectrophotometer (DS Pharma Biomedical Co, Ltd). 
Statistical analysis

Data are expressed as mean \pm standard error of the mean (SEM). Differences between treatment groups were identified using unpaired $t$-tests. Multiple comparisons were performed using one-way analysis of variance (ANOVA) followed by Bonferroni's multiple comparison tests. A $p$ value of $<0.05$ was considered to be statistically significant.

\section{Results}

Moderate hypoxia decreased IL-6 secretion with the increase in HIF1 $\alpha$ expression Initially, we examined the effect of moderate hypoxia $\left(5 \% \mathrm{O}_{2}\right)$ on the human trophoblast cell line compared with normal $\mathrm{O}_{2}$ tension $\left(21 \% \mathrm{O}_{2}\right)$ conditions for $24 \mathrm{~h}$ and $48 \mathrm{~h}$. Cells subjected to moderate hypoxia released low levels of IL-6 compared with cells maintained under normoxia (Fig. 1A). On the other hand, other inflammatory cytokines involving IL-1 $\beta$ and IL-8 and anti-inflammatory cytokine IL-10 did not differ between these conditions (data not shown). As expected, a higher number of pimonidazole (a hypoxia marker) -positive cells were observed under the conditions of moderate hypoxia than those under the conditions of normoxia (Fig. 1B), indicating that a $5 \% \mathrm{O}_{2}$ condition is appropriate for inducing hypoxic conditions. HIF $1 \alpha$, a key regulator of the cellular response to hypoxia, was expressed under the conditions of moderate hypoxia but not under those of normoxia (Fig. 1C). Moreover, the cells subjected to moderate hypoxia were treated with $\mathrm{CoCl}_{2}$, a chemical inducer of HIF1 $\alpha$, resulting in the induction of HIF1 $\alpha$ protein compared with the control under moderate hypoxia (Fig. 1C). On the other hand, anti-tumor agent PX-12, a known chemical suppressor of HIF1 $\alpha$ activity, clearly decreased HIF1 $\alpha$ protein under moderate hypoxia. Under normal $\mathrm{O}_{2}$ tension, we did not see a clear change in HIF1 $\alpha$ protein (Fig. 1C) because HIF- $1 \alpha$ protein is degraded in normoxic conditions but stabilized under hypoxic conditions [23].

Moderate hypoxia attenuated LPS-induced IL-6 secretion with the suppression of TLR4

LPS clearly stimulated IL-6 secretion from the human trophoblast cell line in a timedependent manner (Fig. 2A). Cells subjected to moderate hypoxia decreased the levels of LPSinduced IL- 6 secretion compared with in cells maintained under normoxia. To investigate the reason for low levels of IL-6 secretion under the conditions of moderate hypoxia, we showed

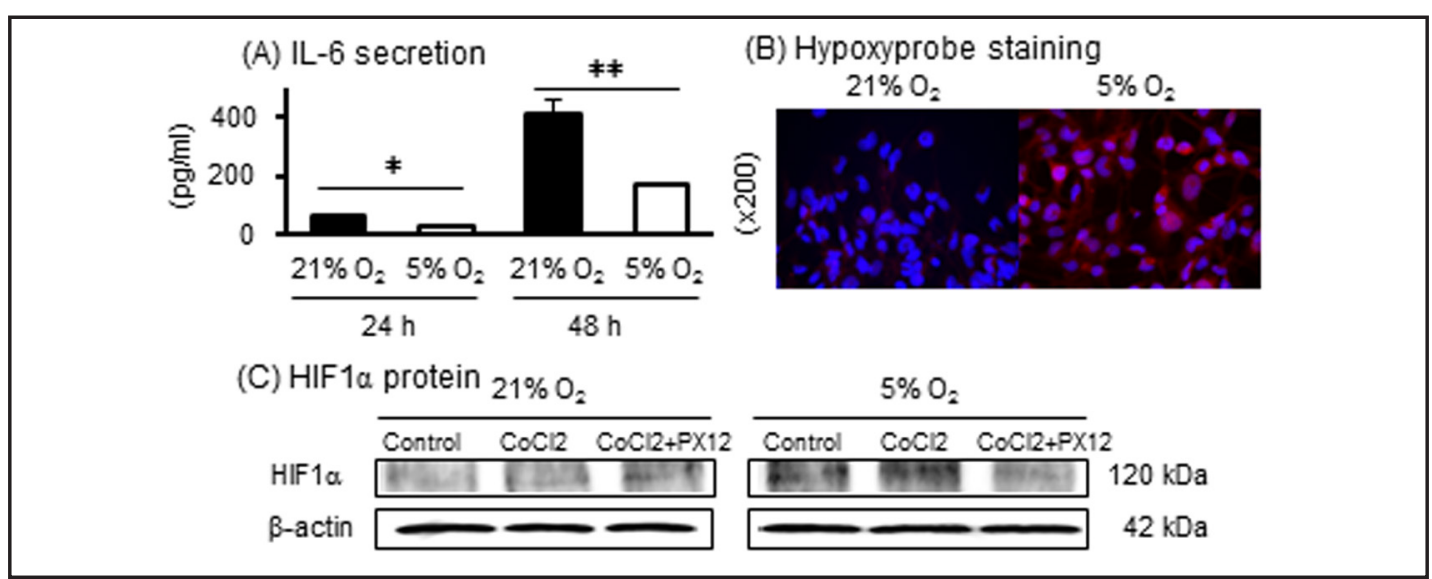

Fig. 1. Effects of moderate hypoxia on IL-6 secretion and HIF1 $\alpha$ expression. (A) Sw.71 trophoblast cells were incubated for $24 \mathrm{~h}$ or $48 \mathrm{~h}$ under normoxia or moderate hypoxia conditions. IL-6 levels in supernatants were determined. (B) After $48 \mathrm{~h}$ incubation under normoxia or moderate hypoxia conditions, hypoxic condition was confirmed using a hypoxyprobe staining kit (Hypoxyprobe-1 mAb1) with DAPI. (C) Representative HIF1 $\alpha$ and $\beta$-actin immunoblots conditioned at $21 \%$ or $5 \% \mathrm{O}_{2}$ in the presence or absence of $\mathrm{CoCl}_{2}$ and PX12. Black bars indicate normoxia and white bars indicate moderate hypoxia. Data are expressed as means \pm SEM $(\mathrm{n}=3)$; Significant differences were identified using the t-test; ${ }^{*} \mathrm{p}<0.05$ and ${ }^{* *} \mathrm{p}<0.01$. 


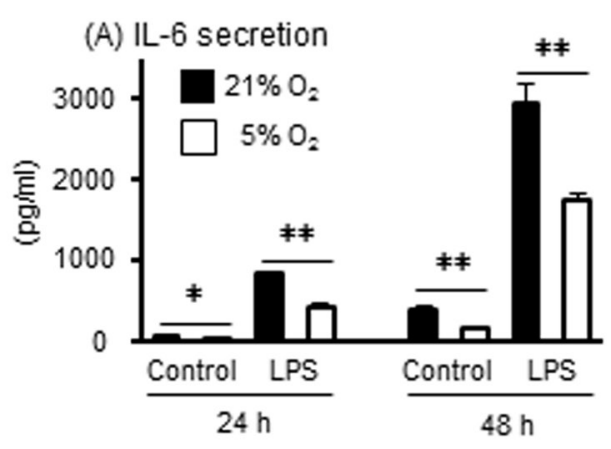

(B) TLR4 protein

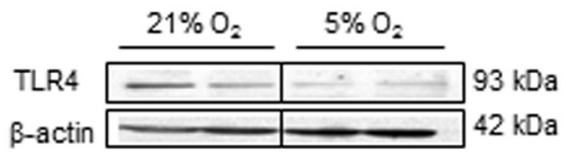

(C) TLR4 expression

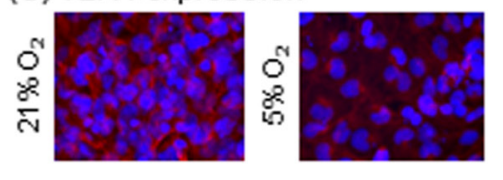

Fig. 2. Effects of moderate hypoxia on LPS-induced IL-6 secretion and TLR4 expression. (A) Sw.71 trophoblast cells were incubated for $24 \mathrm{~h}$ or $48 \mathrm{~h}$ in the presence of LPS (100 ng/mL) stimulation under normoxia or moderate hypoxia conditions. IL-6 levels were determined. (B) Representative TLR4 and $\beta$-actin immunoblots conditioned at $21 \%$ or $5 \% \mathrm{O}_{2}$ for $48 \mathrm{~h}$. (C) Sw.71 trophoblast cells were incubated for $48 \mathrm{~h}$ under normoxia or moderate hypoxia conditions; cells were stained with TLR4 antibody with DAPI. Black bars indicate normoxia and white bars indicate moderate hypoxia. Data are expressed as means \pm SEM $(n=3)$; significant differences were identified using the t-test; ${ }^{*} \mathrm{p}<0.05$ and ${ }^{* *} \mathrm{p}<0.01$.

Fig. 3. IL-6 secretion and TLR4 expression by chemical regulators of HIF1 $\alpha$. (A) Sw.71 trophoblast cells were incubated in the presence or absence of $\mathrm{CoCl}_{2}$ or deferoxiamin at the indicated concentrations under normoxia. IL-6 levels were determined. (B) Representative TLR4 and $\beta$-actin immunoblots were conditioned for $48 \mathrm{~h}$ in the presence or absence of $\mathrm{CoCl}_{2}$ or deferoxiamin under normoxia. (C) Cells were incubated in the presence or absence of $\mathrm{CoCl}_{2}(50 \mu \mathrm{M})$ with or without PX-12 at the indicated concentrations under normoxia or moderate hypoxia. IL-6 levels were determined. Black bars indicate normoxia and white bars indicate moderate hypoxia. Data are expressed as means \pm SEM ( $n=3-4)$; Significant differences were identified using ANOVA followed by Bonferroni's multiple comparison test; ${ }^{*} \mathrm{p}<0.05$ and $* * \mathrm{p}<0.01$.
(A) IL-6 secretion by HIF1 activators
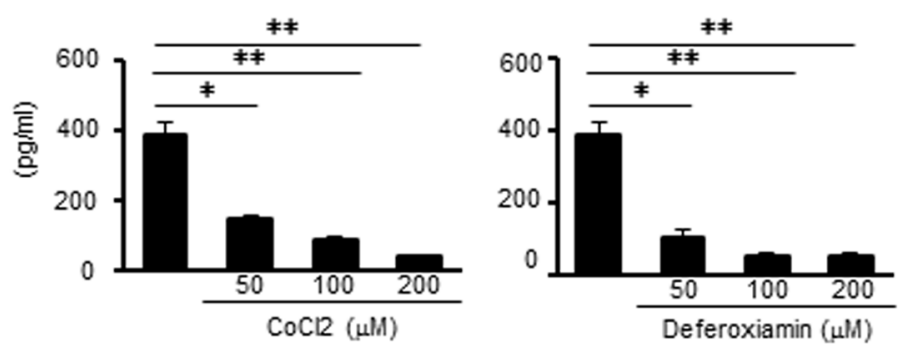

(B) TLR4 protein

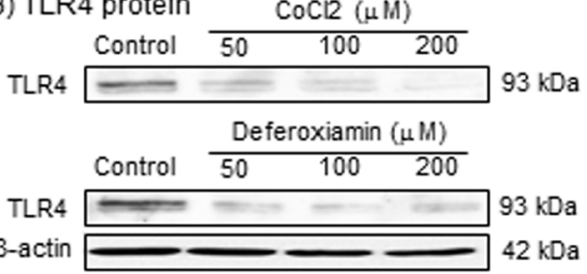

(C) IL-6 secretion by HIF1 inhibitor
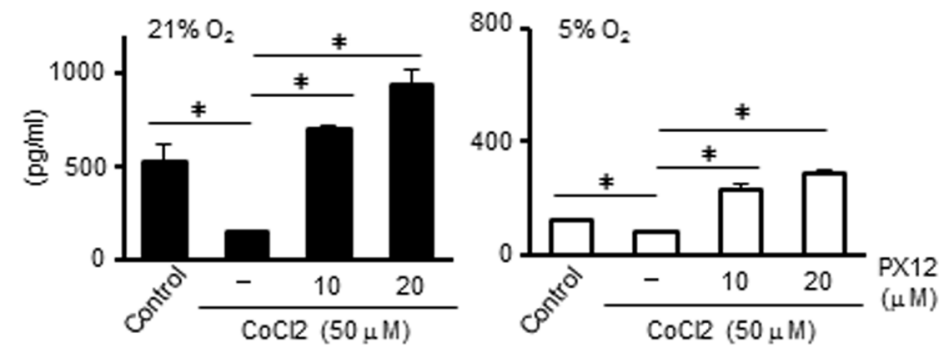

the decrease of TLR4 protein expression under moderate hypoxia conditions compared with that under normoxia, as evaluated by western blotting (Fig. 2B) and immunofluorescence (Fig. 2C). These finding suggest that moderate hypoxia controlled IL-6 secretion and TLR4 expression in human trophoblast cells.

\section{KARGER}


Fig. 4. Role of ROS on IL-6 secretion. (A) Sw.71 trophoblast cells were incubated for 48 $h$ in the presence or absence of LPS (100 ng/mL) under normoxia and moderate hypoxia. ROS production was analyzed using CellROX Oxidative Stress Reagents with DAPI. (B) Cells were incubated for $48 \mathrm{~h}$ in the presence or absence of rotenone or pyocianin at the indicated concentrations under normoxia or moderate hypoxia. (C) Cells were incubated in the presence or absence of NAC ( $5 \mathrm{mM})$ or LPS (100 ng/mL) under normoxia and moderate hypoxia. IL- 6 levels were determined. Black bars indicate normoxia and white bars indicate moderate hypoxia. Data are expressed as means \pm SEM $(n=3-4)$; significant differences were identified using ANOVA followed by Bonferroni's multiple comparison test; ${ }^{*} \mathrm{p}<0.05$ and $^{* *} \mathrm{p}<0.01$.

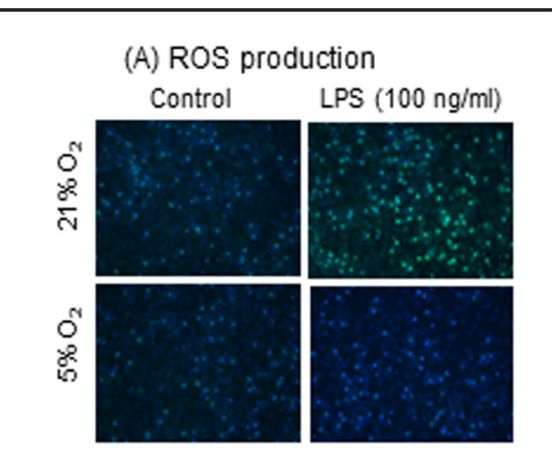

(B) IL-6 secretion by ROS stimulators
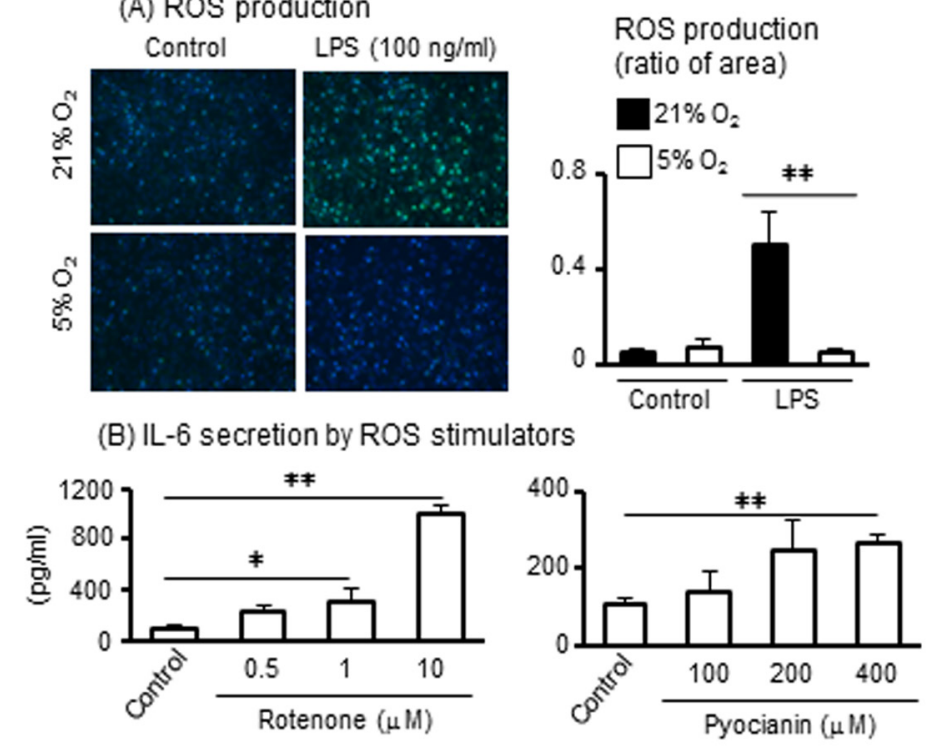

(C) IL-6 secretion by anti-oxidant NAC .
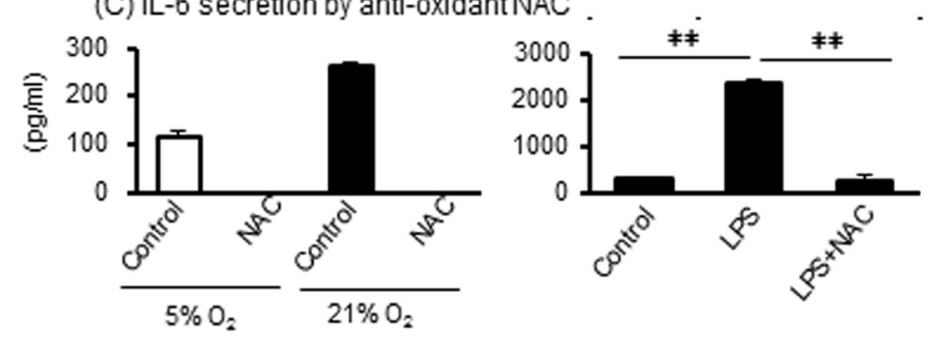

Inflammatory conditions of trophoblast cells are regulated by HIF1 $\alpha$ activation

We hypothesized that HIF1 $\alpha$ relates to the decrease in IL-6 secretion because moderate hypoxia diminished IL- 6 secretion. Thus, we investigated the effect of HIF1 $\alpha$ activators such as $\mathrm{CoCl}_{2}$ and deferoxiamin on IL- 6 secretion cultured under normoxic conditions. Treatment with $\mathrm{CoCl}_{2}$ and deferoxiamin drastically inhibited IL-6 secretion in the supernatant (Fig. 3A). In addition, these activators of HIF1 $\alpha$ clearly decreased TLR4 protein expression in a dosedependent manner (Fig. 3B). We next examined the inhibitory effect of HIF1 $\alpha$ using PX-12. Although $\mathrm{CoCl}_{2}$ inhibited IL-6 secretion, this effect of $\mathrm{CoCl}_{2}$ was reversed with treatment of PX-12 in both conditions of normoxia and moderate hypoxia (Fig. 3C). These findings indicate the possibility that HIF1 $\alpha$ regulates IL-6 secretion with TLR4 expression in human trophoblast cells.

\section{ROS production is essential for IL-6 secretion}

The data indicating that increased IL-6 secretion under normal $\mathrm{O}_{2}$ tension led us to hypothesize that ROS production involves IL-6 secretion in human trophoblast cells. Under $5 \% \mathrm{O}_{2}$ conditions, ROS production was significantly lower following treatment with LPS compared with that under normal culture conditions of $21 \% \mathrm{O}_{2}$ (Fig. 4A). ROS production was not induced in the control groups, both under the conditions of moderate hypoxia and of normoxia. We next examined the effects of ROS inducers, including Rotenone and Pyocianin. Both ROS inducers clearly stimulated IL-6 secretion in a dose-dependent manner (Fig. 4B). To investigate the importance of ROS for IL- 6 secretion, we tested the effect of anti-oxidant NAC on human trophoblast cells. The treatment with NAC drastically decreased IL- 6 secretion under conditions both of moderate hypoxia and of normoxia (Fig. 4C). In addition, treatment of NAC suppressed LPS-induced IL-6 secretion in cells subjected to normoxia. These data 
(A) Cell proliferation

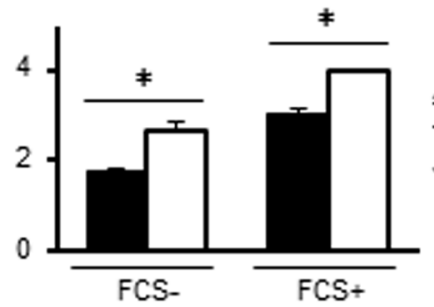

(B) sEng secretion

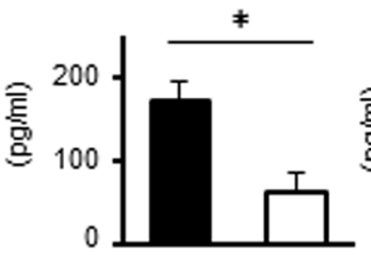

(C) sFlt-1 secretion

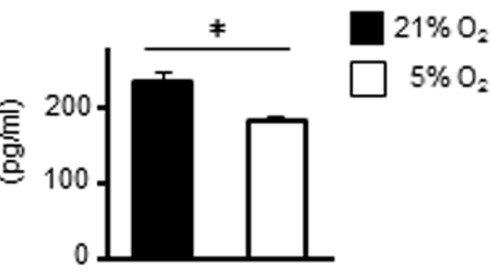

Fig. 5. Effects of moderate hypoxia on cell proliferation and anti-angiogenic factors. (A) Sw.71 trophoblast cells were incubated in the presence or absence of FCS (5\%) under normoxia or moderate hypoxia. Cell proliferation was assessed using a WST1. (B and C) Cells were incubated for $48 \mathrm{~h}$ under normoxia or moderate hypoxia conditions. sEng and sFlt-1 levels were determined. Black bars indicate normoxia and white bars indicate moderate hypoxia. Data are expressed as means \pm SEM $(n=3-4)$; Significant differences were identified using the t-test; ${ }^{*} \mathrm{p}<0.05$.

indicated that ROS production is one of key factors in the induction of IL-6 secretion in human trophoblast cells.

Moderate hypoxia induces cell proliferation and suppresses sEng and sFlt-1 secretion

We determined the effects of moderate hypoxia and normoxia on the proliferation of human trophoblast cells. In culture conditions both with and without FCS, cells subjected to moderate hypoxia increased cell proliferation compared with those maintained under normoxia, as evaluated by WST-1 assay (Fig. 5A).

Finally, we determined sEng and sFlt-1 secretion in this model because high levels of circulating sEng and sFlt-1 of placental origin may contribute to the pathogenesis of preeclampsia, a pregnancy-specific hypertensive syndrome $[7,8]$. In agreement with the data for IL-6 secretion, moderate hypoxia significantly reduced sEng and sFlt-1 secretion for human trophoblast cells (Fig. 5B and C).

\section{Discussion}

Oxygen tension in placental tissues is generally much lower than that found in the atmosphere $[14,15]$. But, it is important to consider that many in vitro experiments are conducted under superoxic conditions of $21 \%$ oxygen [24]. Therefore, we investigated the effects of oxygen tension under moderate hypoxia and normoxia by testing the hypothesis that moderate hypoxia regulates cellular phenotypes differently than normoxia do in the human trophoblast cell line.

In the present study, we first examined IL-6 secretion from human Sw.71 cells because the crucial role of IL-6 on pathogenesis of preeclampsia [25]. In the present study, we showed the novel finding that IL-6 secretion was lower under the conditions of moderate hypoxia than under those of normoxia. Although LPS clearly stimulated IL-6 secretion from the human trophoblast cell line, cells subjected to moderate hypoxia decreased the levels of LPS-induced IL-6 secretion compared with in cells maintained under normoxia. These data suggest that spontaneous and/or LPS-stimulated IL-6 secretion in trophoblast cells are regulated depending on $\mathrm{O}_{2}$ tension.

TLRs are modulated dynamically in response to pathogens, cytokines, and environmental stresses [26]. TLR4 is a key component for innate immunity because LPS induces a severe inflammatory response by initiating multiple intracellular signaling including NF- $\kappa B$ and release of many proinflammatory cytokines such as IL-6, IL-1 $\beta$, IL-8, and TNF $\alpha$ [26]. In the present study, moderate hypoxia and the hypoxic mimesis using $\mathrm{CoCl}_{2}$ and deferoxiamin significantly decreased TLR4 expression and LPS-induced inflammatory response for $48 \mathrm{~h}$ 
in human trophoblast cells. Similarly, Ishida et al. [27] showed that TLR4 mRNA and protein expression was decreased cultured for 48-72 h under hypoxic conditions. In addition, Grodzki et al. [28] suggested that THP-1 macrophages are better primed for responding to an inflammatory signal under normoxic conditions because NF- $\kappa \mathrm{B}$ activation and secretion of cytokines were attenuated in cells exposed to $5 \% \mathrm{O}_{2}$ relative to $18 \% \mathrm{O}_{2}$. These findings suggest that moderate hypoxia may have the potential to regulate the inflammatory response via controlling TLR4 expression. In contrast, Kim et al. [20] indicated that severe hypoxia and $\mathrm{CoCl}_{2}$ acutely enhanced the expression of TLR4 mRNA and protein for 2-8 $\mathrm{h}$ in macrophages. They also demonstrated that HIF $1 \alpha$ bound to the TLR4 promoter region under severe hypoxia and up-regulation of TLR4 by hypoxic stress increased LPS responses in macrophages [20]. Although we could not completely explain these differences in the mechanism of TLR4 expression by hypoxic stress, we considered the possible reasons that some experimental differences involving (1) $\mathrm{O}_{2}$ concentrations; (2) the duration of hypoxia; and (3) the types of cells, which may account for differential cellular responses in TLR4 expression.

ROS are commonly considered harmful mediators of acute inflammation. In the present study, IL-6 secretion was higher under normoxia compared with that under moderate hypoxia, hypothetically implicating the participation of ROS production cultured by superoxic condition in trophoblast cells. Contrary to our expectation, ROS production did not differ between normoxia and moderate hypoxia in the control. Interestingly, LPS stimulated ROS production only under normoxia in trophoblast cells. Similarly, although there was no significant difference in ROS production between $20 \%$ and $5 \% \mathrm{O}_{2}$ conditions in the wildtype astrocytes, ROS production was much higher under $20 \% \mathrm{O}_{2}$ conditions compared with that under $5 \% \mathrm{O}_{2}$ conditions in the manganese superoxide dismutas-/- astrocytes [29]. Therefore, we suggest that under normoxic conditions, ROS production in cells is better primed for responding to an inflammatory signal and/or cellular stresses. In addition, the data in the current study showed that chemical inducers of ROS stimulated IL- 6 secretion and the treatment of anti-oxidant NAC deleted IL- 6 secretion, indicating the importance of ROS production for IL- 6 secretion in trophoblast cells.

James et al, [2] demonstrated that moderate hypoxia as a control may more closely represent physiological conditions in vivo. In addition, Shen et al,[30] suggested considering low $\mathrm{O}_{2}(2.5 \%)$ is a state more closely mimicking in vivo condition using HTR-8/SVneo trophoblast cells. In the present study, moderate hypoxia clearly increased the proliferation of human trophoblast cells. Several different lines of evidences support the hypothesis that hypoxia promotes trophoblast cell proliferation because the hypoxic condition increases proliferation [31], DNA synthesis [32], and 5-bromo-2'-deoxyuridine incorporation [33] in trophoblast cells. Also, in colon carcinoma Caco2 cells, mild hypoxia $\left(6 \% \mathrm{O}_{2}\right)$ induced cell proliferation with the increase of HIF1 $\alpha$ and activation of MEK-Erk signals [34]. Therefore, cellular functions and phenotypes are tightly regulated by oxygen tension, and the sensitivity to oxygen may be different among the cell types. Importantly, Yoshida et al. [35] demonstrated that moderate hypoxic conditions $\left(5 \% \mathrm{O}_{2}\right)$ can improve the efficiency of induced pluripotent stem (iPS) cell generation from mouse and human somatic cells. Parrinello et al. [36] indicated that mouse embryonic fibroblasts did not senesce, nor did any DNA damage occur at physiological (3\%) oxygen levels; however, they underwent a spontaneous event under the conditions of $20 \%$ oxygen. Thus, we have to consider the optimal $\mathrm{O}_{2}$ concentration and investigate various oxygen conditions to understand the basis of the effects of hypoxia.

It is well known that trophoblast differentiation is important for the success of pregnancy, and hypoxia appears to play a role in modulating differentiation of trophoblast. Indeed, moderate hypoxia has been shown to decrease the invasive capacity of trophoblast cells compared with under normoxia $[2,33]$. In contrast, sever hypoxia increased the invasion of HTR-8/SVneo trophoblast cells by up regulating urokinase-type plasminogen activator [37]. On the other hand, transforming growth factor- $\beta$ (TGFB) is well investigated as an essential cytokines in regulating trophoblast differentiative phenotype. TGFB has three isoforms including TGFB1, TGFB2 and TGFB3. It is reported that induction of HIF-1 $\alpha$ by 


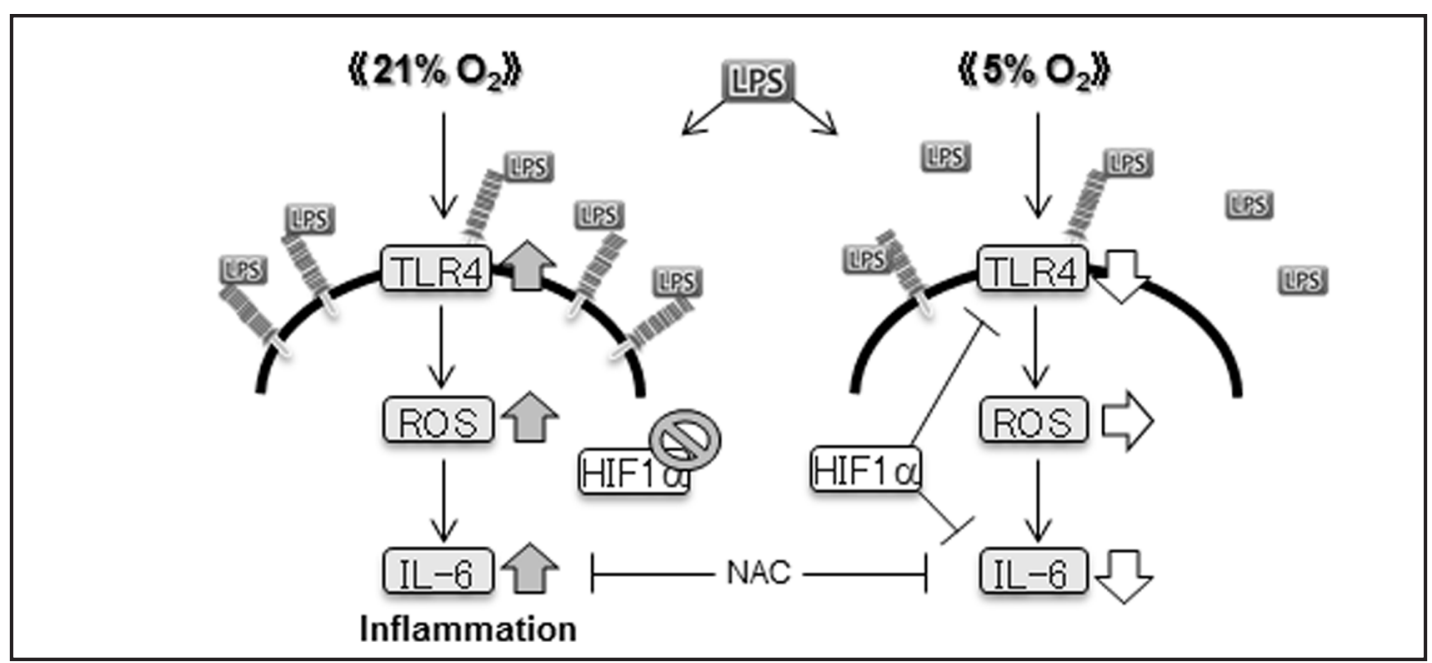

Fig. 6. Proposed mechanism underlying the effect of normoxia and moderate hypoxia. A schematic summary of the present study are shown in Figure 6. Spontaneous and/or LPS-stimulated TLR4 expression, ROS production, and IL- 6 secretion, are down-regulated by moderate hypoxia, and HIF1 $\alpha$ and ROS have the potential to regulate these responses in human trophoblast cells.

hypoxia associated with the increase of TGFB3 expression, and this TGFB3 down-regulated trophoblast invasion [1]. On the other hand, TGFB1 has a capacity to stabilize HIF1 $\alpha$ protein under nomoxic conditions [38]. However, the function of TGFB1 is controversial because TGFB1 did not alter the extent of trophoblast invasion on primary isolated trophoblast cells [39] whereas it had inhibitory effects on trophoblast invasion via RhoA/Rho-associated kinase pathway [40]. Therefore, the regulation of trophoblast differentiation by hypoxia or HIF1 $\alpha$ may be complex mechanisms including hypoxic-related factors and cytokines.

Increasing evidence indicates that severe hypoxic conditions induce an increase in the level of sEng and sFlt-1 from trophoblast cells, compared with normoxia as a control [9, $10,41]$. Murphy et al. [41] reported that sFlt-1 production from rat placenta under hypoxic condition $\left(1 \% \mathrm{O}_{2}\right)$ was significantly increased compared with under $6 \% \mathrm{O}_{2}$ condition used as a control. On the other hand, the secretion of sEng and sFlt-1 significantly decreased under the conditions of $5 \% \mathrm{O}_{2}$ when compared with that under the conditions of $21 \% \mathrm{O}_{2}$ in the present study. We emphasized that high oxygen concentration $\left(21 \% \mathrm{O}_{2}\right)$ might induce the increase of preeclampsia-related factors with inflammatory responses in the cultured trophoblast cells, therefore, to evaluate the effect of very low oxygen $\left(1-2 \% \mathrm{O}_{2}\right)$ on the cell function, we should consider oxygen concentration as controls. We should further evaluate the cell status in not only pathophysiological/severe hypoxia $\left(1-2 \% \mathrm{O}_{2}\right)$, but also physiological/moderate hypoxic oxygen concentration $\left(5 \% \mathrm{O}_{2}\right)$.

It is well known that hypoxia, with the increase of HIF1 $\alpha$, is closely associated with inflammatory conditions and pathogenesis. In contrast, Tannahill et al. [42] reported that LPS-stimulated IL-6 secretion was inhibited under the conditions of hypoxia compared with those of normoxia in bone marrow-derived macrophages, and we also showed that moderate hypoxic conditions and chemical HIF1 activators down-regulated inflammatory responses in trophoblast cells. Recently, Hart et al. [43] reported that in the intestinal ischemia/reperfusion (IR) model, HIF-/- mice demonstrated significantly higher levels of IL-6 compared with wild-type mice and pharmacological HIF1 $\alpha$ activation protected intestinal IR injury with the suppression of IL-6. Moreover, cardiac HIF1 $\alpha$ suppression by siRNA technique in vivo revealed an abolished cardioprotection by ischemic preconditioning [44]. As an important regulator of oxygen homeostasis, HIF1 has been implicated in transcriptional regulation of anti-inflammatory signaling pathways [45]. These findings suggest that HIF1 plays a critical protective role in anti-inflammatory response and tissue repair as well as induction of inflammation. 
In conclusion, as shown in Figure 6, IL-6 secretion, TLR4 expression, and ROS production, which are classical markers of inflammatory response, are down-regulated by moderate hypoxia, and HIF1 $\alpha$ and ROS have the potential to regulate these responses in human trophoblast cells. We also suggested that the up-regulation of HIF1 $\alpha$ under moderate hypoxia is one of the key candidates to explain the difference in these responses between moderate hypoxia $\left(5 \% \mathrm{O}_{2}\right)$ and normoxia $\left(21 \% \mathrm{O}_{2}\right)$.

\section{Disclosure Statement}

The authors declare no conflict of interest.

\section{Acknowledgments}

This study received grants from the Japan Society for the Promotion of Science (JSPS) through the Grant-in-Aid for Young Scientists (B) (K.S.) and Scientific Research (C) (H.S., and H.I.), and Strategic Research Project from Tokyo University of Agriculture (K.S.).

\section{References}

1 Caniggia I, Winter J, Lye SJ, Post M: Oxygen and placental development during the first trimester: Implications for the pathophysiology of pre-eclampsia. Placenta 2000;21:S25-30.

2 James JL, Stone PR, Chamley LW: The regulation of trophoblast differentiation by oxygen in the first trimester of pregnancy. Hum Reprod Update 2006;12:137-144.

3 Liu L, Zhang X, Rong C, Rui C, Ji H, Qian YJ, Jia R, Sun L: Distinct DNA methylomes of human placentas between pre-eclampsia and gestational diabetes mellitus. Cell Physiol Biochem 2014;34:1877-1889.

4 Miao Z, Chen M, Wu H, Ding H, Shi Z: Comparative proteomic profile of the human placenta in normal and fetal growth restriction subjects. Cell Physiol Biochem 2014;34:1701-1710.

5 Ohkuchi A, Hirashima C, Suzuki H, Takahashi K, Yoshida M, Matsubara S, Suzuki M: Evaluation of a new and automated electrochemiluminescence immunoassay for plasma sflt- 1 and plgf levels in women with preeclampsia. Hypertens Res 2010;33:422-427.

6 Raymond D, Peterson E: A critical review of early-onset and late-onset preeclampsia. Obstet Gynecol Surv 2011;66:497-506.

7 Maynard SE, Min JY, Merchan J, Lim KH, Li J, Mondal S, Libermann TA, Morgan JP, Sellke FW, Stillman IE, Epstein FH, Sukhatme VP, Karumanchi SA: Excess placental soluble fms-like tyrosine kinase 1 (sflt1) may contribute to endothelial dysfunction, hypertension, and proteinuria in preeclampsia. J Clin Invest 2003;111:649-658.

8 Venkatesha S, Toporsian M, Lam C, Hanai J, Mammoto T, Kim YM, Bdolah Y, Lim KH, Yuan HT, Libermann TA, Stillman IE, Roberts D, D'Amore PA, Epstein FH, Sellke FW, Romero R, Sukhatme VP, Letarte M, Karumanchi SA: Soluble endoglin contributes to the pathogenesis of preeclampsia. Nat Med 2006;12:642-649.

9 Munaut C, Lorquet S, Pequeux C, Blacher S, Berndt S, Frankenne F, Foidart JM: Hypoxia is responsible for soluble vascular endothelial growth factor receptor-1 (vegfr-1) but not for soluble endoglin induction in villous trophoblast. Hum Reprod 2008;23:1407-1415.

10 Lee DK, Nevo 0: 2-methoxyestradiol regulates vegfr-2 and sflt-1 expression in human placenta. Placenta 2015;36:125-130.

11 Mellembakken JR, Aukrust P, Hestdal K, Ueland T, Abyholm T, Videm V: Chemokines and leukocyte activation in the fetal circulation during preeclampsia. Hypertension 2001;38:394-398.

12 Mor G, Cardenas I, Abrahams V, Guller S: Inflammation and pregnancy: The role of the immune system at the implantation site. Ann N Y Acad Sci 2011;1221:80-87.

13 Laresgoiti-Servitje E: A leading role for the immune system in the pathophysiology of preeclampsia. J Leukoc Biol 2013;94:247-257. 
14 Erecinska M, Silver IA: Tissue oxygen tension and brain sensitivity to hypoxia. Respir Physiol 2001;128:263-276.

15 Braun L, Kardon T, Reisz-Porszasz ZS, Banhegyi G, Mandl J: The regulation of the induction of vascular endothelial growth factor at the onset of diabetes in spontaneously diabetic rats. Life Sci 2001;69:25332542.

16 Rodesch F, Simon P, Donner C, Jauniaux E: Oxygen measurements in endometrial and trophoblastic tissues during early pregnancy. Obstet Gynecol 1992;80:283-285.

17 Semenza GL: Oxygen-dependent regulation of mitochondrial respiration by hypoxia-inducible factor 1. Biochem J 2007;405:1-9.

18 Arck PC, Hecher K: Fetomaternal immune cross-talk and its consequences for maternal and offspring's health. Nat Med 2013;19:548-556.

19 Eiland E, Nzerue C, Faulkner M: Preeclampsia 2012. J Pregnancy 2012;2012:586578.

20 Kim SY, Choi YJ, Joung SM, Lee BH, Jung YS, Lee JY: Hypoxic stress up-regulates the expression of toll-like receptor 4 in macrophages via hypoxia-inducible factor. Immunology 2009;129:516-524.

21 Urner M, Herrmann IK, Booy C, Roth-Z' Graggen B, Maggiorini M, Beck-Schimmer B: Effect of hypoxia and dexamethasone on inflammation and ion transporter function in pulmonary cells. Clin Exp Immunol 2012;169:119-128.

22 Straszewski-Chavez SL, Abrahams VM, Alvero AB, Aldo PB, Ma Y, Guller S, Romero R, Mor G: The isolation and characterization of a novel telomerase immortalized first trimester trophoblast cell line, swan 71. Placenta 2009;30:939-948.

23 Ivan M, Kondo K, Yang H, Kim W, Valiando J, Ohh M, Salic A, Asara JM, Lane WS, Kaelin WG, Jr: Hifalpha targeted for vhl-mediated destruction by proline hydroxylation: Implications for o 2 sensing. Science 2001;292:464-468.

24 Ikejiri A, Nagai S, Goda N, Kurebayashi Y, Osada-Oka M, Takubo K, Suda T, Koyasu S: Dynamic regulation of th17 differentiation by oxygen concentrations. Int Immunol 2011;24:137-146.

25 Orshal JM, Khalil RA: Reduced endothelial no-cgmp-mediated vascular relaxation and hypertension in il-6infused pregnant rats. Hypertension 2004;43:434-444.

26 Akira S, Uematsu S, Takeuchi O: Pathogen recognition and innate immunity. Cell 2006;124:783-801.

27 Ishida I, Kubo H, Suzuki S, Suzuki T, Akashi S, Inoue K, Maeda S, Kikuchi H, Sasaki H, Kondo T: Hypoxia diminishes toll-like receptor 4 expression through reactive oxygen species generated by mitochondria in endothelial cells. J Immunol 2002;169:2069-2075.

28 Grodzki AC, Giulivi C, Lein PJ: Oxygen tension modulates differentiation and primary macrophage functions in the human monocytic thp-1 cell line. PLoS One 2013;8:e54926.

29 Liu J, Narasimhan P, Lee YS, Song YS, Endo H, Yu F, Chan PH: Mild hypoxia promotes survival and proliferation of sod2-deficient astrocytes via c-myc activation. J Neurosci 2006;26:4329-4337.

30 Shen Z, Wu Y, Chen X, Chang X, Zhou Q, Zhou J, Ying H, Zheng J, Duan T, Wang K: Decreased maternal serum 2-methoxyestradiol levels are associated with the development of preeclampsia. Cell Physiol Biochem 2014;34:2189-2199.

31 Kilburn BA, Wang J, Duniec-Dmuchowski ZM, Leach RE, Romero R, Armant DR: Extracellular matrix composition and hypoxia regulate the expression of hla-g and integrins in a human trophoblast cell line. Biol Reprod 2000;62:739-747.

32 Jiang B, Kamat A, Mendelson CR: Hypoxia prevents induction of aromatase expression in human trophoblast cells in culture: Potential inhibitory role of the hypoxia-inducible transcription factor mash-2 (mammalian achaete-scute homologous protein-2). Mol Endocrinol 2000;14:1661-1673.

33 Genbacev 0, Zhou Y, Ludlow JW, Fisher SJ: Regulation of human placental development by oxygen tension. Science 1997;277:1669-1672.

34 Miyamoto L, Yagi Y, Hatano A, Kawazoe K, Ishizawa K, Minakuchi K, Tomita S, Tsuchiya K: Spontaneously hyperactive mek-erk pathway mediates paradoxical facilitation of cell proliferation in mild hypoxia. Biochim Biophys Acta 2014;1850:640-646.

35 Yoshida Y, Takahashi K, Okita K, Ichisaka T, Yamanaka S: Hypoxia enhances the generation of induced pluripotent stem cells. Cell Stem Cell 2009;5:237-241.

36 Parrinello S, Samper E, Krtolica A, Goldstein J, Melov S, Campisi J: Oxygen sensitivity severely limits the replicative lifespan of murine fibroblasts. Nat Cell Biol 2003;5:741-747. 


\section{Cellular Physiology Cell Physiol Biochem 2015;36:2149-2160 \begin{tabular}{l|l} 
and Biochemistry $10.1159 / 000430181$ & $\begin{array}{l}\text { D 2015 S. Karger AG, Basel } \\
\text { Published online: July 21, 2015 }\end{array}$ \\
\cline { 2 - 3 } & www.karger.com/cpb
\end{tabular} \\ Shirasuna et al.: Moderate Hypoxia Suppresses Inflammatory Response}

37 Graham CH, Fitzpatrick TE, McCrae KR: Hypoxia stimulates urokinase receptor expression through a heme protein-dependent pathway. Blood 1998;91:3300-3307.

38 Patel J, Landers K, Mortimer RH, Richard K: Regulation of hypoxia inducible factors (hif) in hypoxia and normoxia during placental development. Placenta 2010;31:951-957.

39 Bass KE, Morrish D, Roth I, Bhardwaj D, Taylor R, Zhou Y, Fisher SJ: Human cytotrophoblast invasion is up-regulated by epidermal growth factor: Evidence that paracrine factors modify this process. Dev Biol 1994;164:550-561.

40 Fafet P, Rebouissou C, Maudelonde T, Vignais ML: Opposite effects of transforming growth factor-beta activation and rho-associated kinase inhibition on human trophoblast migration in a reconstituted placental-endometrial coculture system. Endocrinology 2008;149:4475-4485.

41 Murphy SR, LaMarca BB, Parrish M, Cockrell K, Granger JP: Control of soluble fms-like tyrosine-1 (sflt-1) production response to placental ischemia/hypoxia: Role of tumor necrosis factor-alpha. Am J Physiol Regul Integr Comp Physiol 2013;304:R130-135.

42 Tannahill GM, Curtis AM, Adamik J, Palsson-McDermott EM, McGettrick AF, Goel G, Frezza C, Bernard NJ, Kelly B, Foley NH, Zheng L, Gardet A, Tong Z, Jany SS, Corr SC, Haneklaus M, Caffrey BE, Pierce K, Walmsley S, Beasley FC, Cummins E, Nizet V, Whyte M, Taylor CT, Lin H, Masters SL, Gottlieb E, Kelly VP, Clish C, Auron PE, Xavier RJ, O'Neill LA: Succinate is an inflammatory signal that induces il-1beta through hif-1alpha. Nature 2013;496:238-242.

43 Hart ML, Grenz A, Gorzolla IC, Schittenhelm J, Dalton JH, Eltzschig HK: Hypoxia-inducible factor-1alphadependent protection from intestinal ischemia/reperfusion injury involves ecto-5'-nucleotidase (cd73) and the a2b adenosine receptor. J Immunol 2011;186:4367-4374.

44 Eckle T, Kohler D, Lehmann R, El Kasmi K, Eltzschig HK: Hypoxia-inducible factor-1 is central to cardioprotection: A new paradigm for ischemic preconditioning. Circulation 2008;118:166-175.

45 Sitkovsky M, Lukashev D: Regulation of immune cells by local-tissue oxygen tension: Hif1 alpha and adenosine receptors. Nat Rev Immunol 2005;5:712-721. 